\title{
About Law Enforcement
}

\section{Vladimir Valentinovich Kozhevnikov}

Department of Theory and History of State and Law, Omsk State University Dostoevsky, Omsk, Russia

Email:kta6973@rambler.ru

\section{Abstract:}

The article examines a number of features of law enforcement in the law enforcement sphere. In particular, the author touched upon the subject composition of law enforcement activities, as well as its participants (victims, witnesses, etc.), on whose legal activity the effectiveness of law enforcement activities largely depends. Attention is drawn to the professional and psychological culture of law enforcement entities, to the regulatory framework of law enforcement, and its peculiarities. stages, structure of law enforcement acts.

Keywords:

application of law, law enforcement sphere, participants of law enforcement activity, normative basis of law enforcement, structure of acts of law enforcement

\section{Introduction}

It seems that the relevance of the presented article is due to the importance of the application of the norms of law in the operational-executive and law enforcement sectors in the work of the legal regulation mechanism. The peculiarities of law enforcement in the law enforcement sphere are determined by the specifics of the latter, which is associated with the facts of the commission of offenses. Unfortunately, we have to admit that the former are often not taken into account by modern theoretical scientists.

\section{Research Methods}

When preparing a scientific article, the following methods were used:

1. general philosophical (dialectical-materialistic), which is used in all social sciences;

2. general scientific (analysis and synthesis, logical and historical, comparisons, abstractions, etc.), which are used not only by the theory of state and law, but also by other social sciences;

3. special methods (philological, cybernetic, psychological, etc.), developed by special sciences and widely used for the knowledge of state and legal phenomena;

4. private scientific (formal legal, interpretation of law, etc.), which are developed by the theory of state and law.

\section{Discussion}

Subjects and participants of law enforcement in the law enforcement sphere. Firstly, this concerns the subjects of law enforcement, which are only competent law enforcement agencies (police, prosecutors, etc.) and their officials.

It is not difficult to notice that in this case we exclude other subjects that are mentioned by the authors when formulating law enforcement. So, Vladimir Ivanovich Chervonyuk argues 


\section{Polit Journal: Scientific Journal of Politics \\ ISSN: 2775-5843 (Online), 2775-5835 (Print)}

Vol. 1, No. 2, May 2021, Page: 69-73

Email: politjournal2@gmail.com

that "the application of law is the power activity of state bodies, their officials and other authorized subjects" [1].

Secondly, law enforcement in the law enforcement sphere objectively actualizes the role and importance of its participants (victims, witnesses, attesting witnesses, etc.), whose positive legal activity largely determines the effectiveness of this legal activity. However, we have to admit that this is not taken into account by scientists when analyzing the system of factors of the effectiveness of law enforcement. For example, Yevgeny Alekseevich Mamai, characterizing the conditions of efficiency related to the subjective side of the law enforcement procedure, only by the provision that "the problem of the effectiveness of law enforcement procedures in terms of their subjective side is limited mainly by the problems of taking into account the motivation of the participants in the procedure and influencing it in order to optimize the flow procedures" [2].

Professional and psychological culture of law enforcement entities. The need to take into account the law-active behavior of participants in the law enforcement process presupposes that law enforcement officials have a professional and psychological culture, which, along with the professional legal, professional moral and other parts, determines the professional culture of the persons concerned.

Psychological training of law enforcement officials, involving an arsenal of tactics, helps to increase the legal activity of participants in law enforcement, aimed at disclosing and investigating crimes, considering administrative cases. Noting that law enforcement is full of extreme situations that significantly affect the person and her activities, Alexander Fedorovich Karavaev notes that in extreme conditions, employees have to perform extremely difficult tasks that require them to return physical, psychological and spiritual strength. Therefore, they all bear an increased measure of moral responsibility and need psychological stability, self- control, selfconfidence [3].

Normative basis of law enforcement in the law enforcement sphere. Often, theoretical scientists do not take into account that the regulatory framework in this area is not limited only to the rule of law. So the group of authors - Timofey Nikolaevich Radko, Valery Vasilievich Lazarev and Lyudmila Aleksandrovna Morozova, believing that "law enforcement is the solution of a specific case, a life case, a specific legal situation; application of legal norms to specific persons and circumstances ", emphasizes that as the most typical case of application of law, one can point to the activity of the court to consider the case and make the appropriate decision [4]. We believe that in this case, the normative basis of law enforcement is not only legal norms, but also the norms of morality, traditions, customs and other non-legal regulators of social relations, which in some cases require consideration by the law enforcement entity. Valery Vasilyevich Lazarev quite reasonably notes that \&quot;in some cases, the effectiveness of a law enforcement act will depend solely on how correctly the subject of the application of law takes into account the established customs, formed moral requirements, norms of public organizations, how accurately he establishes the facts of violation of these rules by the relevant persons\&quot; [5].

In law enforcement, situations often arise when, making a decision, the law enforcement officer is dissatisfied with the results, despite the fact that the decision is legal, rea sonable and meets all the requirements. The question arises about the fairness of such a decision, since the fundamental principle of justice is, first of all, its awareness. In cases where the question arises as to whether the made law enforcement decision is fair or unjust, one can conditionally proceed from two approaches, which, however, were considered above: 1 ) determine the fairness of the 
law enforcement act only from the point of view of legality, i.e. compliance with the rule of law. In other words, if the decision is made in the appropriate form, is justified and meets all legal requirements, fits within the framework of a legal norm and does not contradict it, it is fair. Here the concept of legality, as emphasized above, is as close as possible to the category of justice; 2) determine justice not only from the point of view of legal norms, but also taking into account the system of other social guidelines. As rightly believes, Ekaterina Nikolaevna Balashova, when making a decision, in addition to information about facts, information about the norms of law, which is mandatory for establishment and analysis, the law enforcement officer often analyzes information from other social norms (morality, religion, morality, politics, etc.), if they are included into a legal norm, are qualifying features and, accordingly, are obligatory for the establishment and observance of the principle of completeness. It is necessary, from the position of the author, to take into account, analyze and take into account such social norms for making a fair decision, and in the event that they are not directly enshrined in the rule of law, are not qualifying signs and the legislator does not require mandatory analysis of them. This is what, as a rule, the law enforcement officer forgets, the result of which is the adoption of a decision that is legal from the point of view of the legal norm, but unfair from the standpoint of other social guidelines.

Hence, internal contradictions, and external discontent, misunderstanding of both society and people who do not have a legal education and who assess the law enforcement act based on the principle of justice. A law enforcement officer, when passing a law enforcement act, must necessarily analyze the accompanying information contained in the relevant norms of morality, religion, politics, etc., expressing an assessment of qualifying behavior by society, although the obligation to establish, record and analyze it is not always legally enshrined, but in fact during qualification any legally significant actions, this information is taken into account [6].

Stages of law enforcement. As for the stages of law enforcement activity in the law enforcement sphere, attention is drawn to the following peculiarities: a) the sequence of the stages of law enforcement is rather arbitrary, for, for example, there is often a re-qualification of crimes, or the resumption of criminal proceedings due to new or newly discovered circumstances. Commentators of the Criminal Procedure Code of the Russian Federation believe that \&quot; the resumption of criminal proceedings due to new or newly discovered circumstances is one of the exceptional stages of the criminal process, in which the relevant higher court checks the legality and validity of the verdict and other court decisions that have entered into legal force\&quot; [7] ; b) the stage of establishing the factual circumstances necessarily involves the process of proving, that is, the logical activity of establishing and providing evidence, participation in their research and assessment. With the help of evidence, one or another fragment of reality is reproduced, the reconstruction of the circumstances is carried out, which is necessary, in accordance with the requirement of objective truth, for the application of the rules of law. Scientists-proceduralists, believing that the process of proving is the process of establishing the truth in a criminal case, carried out to solve the problems of criminal proceedings, draw attention to the fact that judicial practice indicates that gaps and shortcomings in proof are one of the most common grounds for cancellation higher courts of sentences with the direction of criminal cases for new consideration, as well as their termination [7]; c) taking into account that law enforcement in the law enforcement sphere can very significantly restrict the rights and freedoms of citizens, here such a stage of law enforcement as bringing the decision to the interested parties is actualized. In particular, a number of articles of the RF Criminal Procedure Code are devoted to this stage of law enforcement in the law enforcement sphere. For example, Art. 216 \&quot;Familiarization of the victim, civil plaintiff, civil defendant or their representatives with the materials of the criminal case\&quot;, Art. 217 
\& quot;Familiarization of the accused and his defense lawyer with the materials of the criminal case\&quot; Art. 345 \&quot;Declaration of the verdict\&quot; etc.

The structure of acts of law enforcement in the law enforcement sphere. The content of the law enforcement act determines its structure (Latin structure - structure), i.e. structure and internal form of organization of the system, acting as a unity and stable relationships between its elements [8]. The overwhelming number of Russian scientists, considering the issue of the structure of acts of application, distinguish the following parts to the maximum: introductory, containing the name of the act (sentence, decision, resolution, etc.)

Place and date of adoption, name of the body or official who makes the decision on what case; ascertaining, describing the facts that are the subject of consideration, it is recorded when, where, by whom, under what circumstances and in what ways the act was committed; a motivational one, including an analysis of evidence confirming the presence or absence of factual circumstances, their legal qualification and its justification, an indication of the procedural rules that guided the law enforcement officer, and a resolution fixing the decision on the case (on the legal qualification of acts, on the rights and obligations of measures of legal responsibility for the guilty persons (other measures of state and legal coercion - Vladimir Valentinovich Kozhevnikov) [9]. It seems that in the structure of some acts of law enforcement, especially the main protective ones (for example, a court verdict), the evidentiary part should be distinguished as an independent part, which, as it were, \&quot;wedges\&quot; into the descriptive part of the corresponding legal acts. In practice, it is formulated with an expression such as: \&quot; This is confirmed, for example, by the testimony of a witness.\&quot; We believe that the need for the evidentiary part is conditioned by the circumstance according to which "knowledge of legal facts acquires the character of a conviction in the process of evidentiary activity; the latter includes only true knowledge obtained on the basis of a comprehensive, complete and objective study of the entire set of circumstances of the case (the problem of objective truth).

Therefore, in the process of forming an inner conviction with the help of professional legal consciousness (its criminal law and procedural spheres), a specific group of facts is identified that have the legal property of evidence "[10].

It is interesting to note that scientists who are unwilling to single out the evidentiary part of the acts of application, nevertheless, indirectly recognize it. So, Vladimir Ivanovich Shepelev writes that "the requirement of proving certain legal facts, revealing their validity, truth or falsity is of particular importance" [11].

Valery Vasilievich Lazarev quite reasonably noted that the goal of the first stage (establishment of legal facts and legal structures) is to achieve actual objective truth, and therefore the legislation pays special attention to proving, during which it is recorded which circumstances need to be proved and which do not (well-known, presumptions, prejudices), which facts are proved by strictly defined means (for example, expert examination) [12].

The problem is that the law enforcement officer "cannot observe the factual circumstances directly, because they, as a rule, relate to the past. Therefore, they are supported by evidence - traces of the past, which are material and intangible in nature and are recorded in documents (testimony of witnesses, protocol of inspection of the scene, expert opinion, etc.) "[13]. Thus, we state that the peculiarity of law enforcement in the field of law enforcement is also expressed in the structure of the relevant acts of law enforcement, which, along with other structural parts, includes the evidentiary, which, as it were, "wedges" into the descriptive is 
formed in the following wording: "This is confirmed, for example, by the protocol interrogation, confrontation, etc. ".

\section{Conclusion}

In conclusion of the scientific article, we note that the named features of law enforcement in the law enforcement sphere must be taken into account when studying the relevant topic, especially in higher educational institutions of the police, prosecutor\&\#39; s office and other law enforcement agencies that train practicing lawyers.

\section{References}

[1]. Chervonyuk Vladimir Ivanovich. Theory of state and law: textbook. M.: INFRA-M, 2006.P. 517.

[2]. Mamai Evgeniy Alekseevich. The effectiveness of law enforcement procedures (theory, practice, technique): monograph / under scientific. ed. Vladimir Alekseevich Tolstik. M.: Yurlitinform, 2012.P. 125.

[3]. Karavaev Alexander Fedorovich. Fundamentals of professional development of specialists employees of internal affairs bodies: monograph. Omsk: Omsk Academy of the Ministry of Internal Affairs of the Russian Federation, 2003. P.4

[4]. Radko Timofey Nikolaevich, Lazarev Valery Vasilievich, Morozova Lyudmila Aleksandrovna. Theory of state and law: textbook. M.: Prospect, 2012.P. 272.

[5]. Lazarev Valery Vasilievich. The effectiveness of law enforcement acts // Valery Vasilievich Lazarev. Elected. works in 3 volumes. M .: RIO \&quot;New Justice\&quot;, 2010. V.1. Law, legality. Application of the law. P.138.

[6]. Balashova Ekaterina Nikolaevna. Interaction of legal and non-legal rules of regulation in law enforcement // Legal policy and legal life. 2006.No 4.Pp.70-71.

[7]. Commentary on the Criminal Procedure Code of the Russian Federation / ed. Alexander Ivanovich Bastrykin. M .: Walters Kluver. 2008. Pp.221, 782.

[8]. Philosophical Dictionary / ed. Mark Moiseevich Rosenthal), Moscow: Politizdat, 1975. P. 395.

[9]. Shaburov Anatoly Stepanovich. Implementation, application and interpretation of law // Theory of state and law: textbook / ed. Victor Dmitrievich Perevalov. M. Norma, 2007.P. 243.

[10]. Groshev Alexander Vasilievich. Professional legal awareness of employees of internal affairs bodies (concept, functions, problems of formation): a tutorial. Yekaterinburg: Yekaterinburg. higher. shk. Ministry of Internal Affairs of the Russian Federation, 1985. P. 246.

[11]. Shepelev Vladimir Ivanovich. Implementation of legal norms // Lyubashits Valentin Yakovlevich, Smolensky Mikhail Borisovich, Shepelev Vladimir Ivanovich. Theory of state and law: textbook. Rostov n / a, 2006. P. 426.

[12]. Lazarev Valery Vasilievich. Realization of law // General theory of law: a course of lectures / under the general ed. Vladimir Konstantinovich Babaev. N. Novgorod 1993. P. 364.

[13]. Skakun Olga Fedorovna. Theory of state and law: textbook. Kharkov: Konsum, 2001. P. 425 